\title{
The Effect of Herbal Tea Containing Fenugreek Seed on the Signs of Breast Milk Sufficiency in Iranian Girl Infants
}

\author{
Vida Ghasemi ${ }^{1}$; Masoomeh Kheirkhah ${ }^{2, *} ;$ Mohsen Vahedi $^{3}$ \\ ${ }_{1}^{1}$ Department of Midwifery, School of Nursing and Midwifery, Tehran University of Medical Sciences, Tehran, IR Iran \\ ${ }^{2}$ Department of Midwifery, School of Nursing and Midwifery, Iran University of Medical Sciences, Tehran, IR Iran \\ 3 Gepartment of Midwifery, School of Nursing and Midwifery, Iran University or Medical Sciences, Tehran, IR Iran
Gastroenterology and Liver Diseases Research Center, Shahid Beheshti University of Medical Sciences, Tehran, IR Iran \\ ${ }^{*}$ Corresponding Author: Masoomeh Kheirkhah, Department of Midwifery, School of Nursing and Midwifery, Iran University of Medical Sciences, P. O. Box: 19967-13883, Tehran, IR Iran. \\ Tel:+98-9124137578, Fax:+98-2188201978, E-mail: masoomeh_kheirkhah2002@yahoo.com
}

Received: July 8, 2014; Revised: August 16, 2014; Accepted: September 15, 2014

\begin{abstract}
Background: One of the important reasons behind termination of breast-feeding in the first six months after childbirth is insufficient production of breast milk.

Objectives:Theaim of this study was to determine the effect of herbal tea containing fenugreek seed on the signs of breast milk sufficiency in Iranian girl infants aged 0 - 4 months, at the medical health centers of Tehran university of medical sciences.

Patients and Methods: This study was a clinical trial with a control group. Seventy-eight girl infants, 0 - 4 months old that were exclusively breastfed by their mothers, were randomly assigned to the intervention group (received herbal tea containing $7.5 \mathrm{~g}$ fenugreek seed powder in addition to $3 \mathrm{~g}$ of black tea, three times a day) and the control group (received herbal tea containing $3 \mathrm{~g}$ of black tea powder, three times a day). Before and during the four weeks of study, the signs of breast milk sufficiency were evaluated through measurement of growth parameters and use of follow-up forms for measuring the number of wet diapers in one day, frequency of defecation and infant breast-feeding times in a day.

Results: Before the intervention there was no significant difference between weight, height, head circumference, the number of wet diapers and frequency of defecation between the two groups $(P>0.05)$, yet the number of breast feeding times of the control group was more than the Fenugreek group. At the end of the fourth week in proportion to the pre-intervention conditions, the weight of the infants in the fenugreek group increased significantly from $5282.0513 \pm 1021.51121$ to $6383.0769 \pm 952.06190$, while head circumference increased from $38.3103 \pm 1.62736$ to $39.9256 \pm 1.50660$, number of wet diapers from $5.2821 \pm 0.93044$ to $8.1648 \pm 1.20620$, frequency of defecation from $1.8846 \pm 1.08495$ to $2.7326 \pm 0.94771$ and the number of breast feeding times from $9.1795 \pm 1.39778$ to $15.9597 \pm 1.45056$ ( $\mathrm{P}<0.001$ ). However, there was no significant effect on height variation $(\mathrm{P}=0.078)$. While in the control group there was no significant difference between the mentioned variables $(\mathrm{P}>0.05)$.
\end{abstract}

Conclusions: Herbal tea of fenugreek seed in comparison to the control group improves the signs of breast milk sufficiency.

Keywords: Breast Feeding; Herbal Tea; Fenugreek; Trigonella foenum-graecum

\section{Background}

Breast milk is the most ideal feeding source for infants (1). For ideal and optimized growth of infants, the world health organization (WHO) has recommended that infants should be exclusively breastfed for six months and after that in order to receive nutritious substances, complementary feeding should be added to breast milk for two years (2). Breast-feeding has long and short-term effects on the infants' health. Some of the short-term effects are the decrease of mortality and morbidity, and protection against diseases. Long-term effects of breastfeeding include increase of IQ, decrease of blood pressure, serum cholesterol, obesity during adulthood, type 1 and 2 diabetes, and middle ear and respiratory infections (3-5). The death risk of infants who receive other nutritious substances in addition to breast milk is four times more than infants who are exclusively breast fed (6). De- spite reports showing increase of breast-feeding around the world, from $22 \%$ to $30 \%$ in Saharan Africa and from $30 \%$ to $45 \%$ in America, breast-feeding has still not reached the WHO recommended level $(7,8)$. In Iran, breast-feeding has been reported to be $56.8 \%$ at four months and $27.7 \%$ at six months, respectively. This percentage in rural areas is $58 \%$ at four months and $29 \%$ at six months, and in urban areas it is $56 \%$ and $27 \%$ at four and six months, respectively (9). One of the important reasons of breast feeding termination in the first six months after childbirth is insufficient production of breast milk that is commonly observed in the first four months of life (10). The results of a study from Iran demonstrated that due to mothers' lack of awareness about breast-feeding benefits, sometimes infants may be fed with items other than breast milk such as water, hot water, cold water, sweetened wa-

Copyright ( 2015, Iranian Red Crescent Medical Journal. This is an open-access article distributed under the terms of the Creative Commons Attribution-NonCommercial 4.0 International License (http://creativecommons.org/licenses/by-nc/4.0/) which permits copy and redistribute the material just in noncommercial usages, provided the original work is properly cited. 
ter and pasteurized milk (11). In Iran, the most common reason for breast-feeding termination has been reported to be physicians' lack of emphasis on the importance of breast-feeding in 54\% of cases and real milk insufficiency in $28 \%$ of cases (12). Galactogogues have been used to resolve the problem of milk insufficiency. Galactogogues are medicines or plants that initiate, induce and maintain milk production $(13,14)$. Fenugreek is one the most common sources of galactogogues and belongs to the pea family and has been used for this reason around the world from olden times (14). Fenugreek seed contains trigonelline, choline, prolamin, sapogenin, alkaloid and mucilage fibers. Sapogenins of Fenugreek such as diosgenin and yamogenin have estrogen properties (15). Their exact mechanism of action is unknown. Researchers believe that breast glands are improved sweat glands and fenugreek increases milk production through increase of sweat production. Also, fenugreek seed due to having diosgenin has Phytoestrogen properties. Phytoestrogen has a chemical structure similar to estrogen and can attach to $\alpha$ and $\beta$ receptors and may have estrogenic properties $(13,14,16)$. This plant has been recognized as a safe medicine by the US Food and Drug Administration (17). Studies about galactogogues properties of fenugreek have shown contradictive results. Turkyilmaz's study (2011) showed that milk production in the group who received fenugreek was significantly more than the control group (14). However, Damanik's study in 2008 showed little increase in milk production of the fenugreek group in comparison to the Coleus amboinicus Lour group (18). So far, nothing has been done to investigate the effect of this plant on infant growth parameters, number of wet diapers, frequency of defecation and number of infant breast-feeding times. With regards to the locality, low cost and availability of fenugreek in Iran, this innovative study was conducted with the aim of determining the effect of this plant on breast milk sufficiency signs.

\section{Objectives}

The aim of this study was to determine the effect of herbal tea containing fenugreek seed on the signs of breast milk sufficiency in Iranian girl infants, 0 - 4 months old, at the medical health centers of Tehran University of Medical Science. This study was carried out with the hypothesis that signs of breast milk sufficiency in the fenugreek group are better than the control group.

\section{Patients and Methods}

This study was a double blind randomized clinical trial with a control group. The research sample included 78 girl infants, 0 - 4 months of age, who were referred to the medical health centers affiliated to the Tehran university of medical sciences, located in the south of Tehran city, Tehran, Iran, during 2014. These centers were governmental health providers. This research project was part of a thesis approved by the research council of Tehran university of medical sciences and was approved by the ethics committee of this university (92/D/130/1913) on the $23^{\text {rd }}$ of November 2013. This study was registered in the Iranian Clinical Trial data-base (Irct201312102751n10). The sample size was calculated using the following formula, where power = $80 \%, \alpha=0 / 05$, level of confidence $=95 \%$, case $=\mu_{1}=365.55, s=$ 69.40, control: $\mu_{2}=315.50, s=58.66$ and $(n=39)$.

$$
n=\frac{2 \delta^{2}\left(\mathrm{z}_{1-\frac{\alpha}{2}}+\mathrm{z}_{1-\beta}\right)^{2}}{\left(\mu_{1}-\mu_{2}\right)^{2}}
$$

The inclusion criteria were being a term girl infant aged between 0 and 4 months, having a birth weight between 2500 and $4000 \mathrm{~g}$, normal ability of sucking, and not consuming infant formula, herbal and chemical galactogogues, non-initiation of complementary feeding, and mother and infant not infected by any diseases that have contradiction with breastfeeding. These diseases include infection with human immunity deficiency virus (HIV), addiction to narcotic substances and alcohol, untreated active tuberculosis, using special medicines such as phenobarbital and ergotamine and so on, women under breast cancer treatment, breast problems such as breast nipple indentation, abscess, mastitis, and mother's underlying disease such as asthma, cardiac diseases, blood clotting diseases and diabetes. The exclusion criteria were mother's unwillingness to continue her contribution in the study process and using any galactogogues or infant formula during the study. After obtaining the informed consent and explaining the objectives of the research, the samples were randomly assigned to the intervention (received herbal tea containing $7.5 \mathrm{~g}$ fenugreek seed powder in addition to $3 \mathrm{~g}$ of black tea, three times a day) or the control group (received herbal tea containing $3 \mathrm{~g}$ of black tea powder, three times a day) (Figure 1).

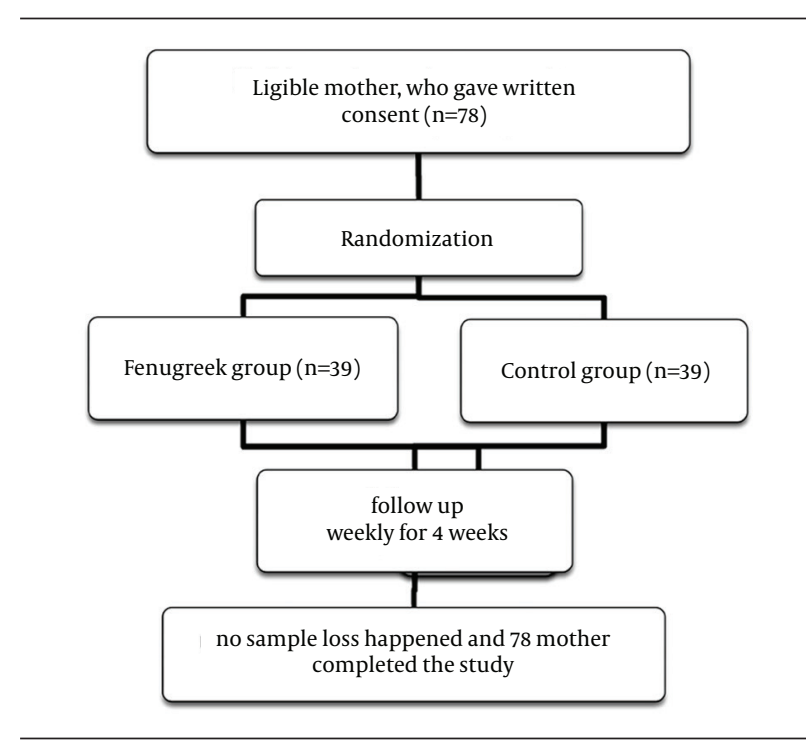

Figure 1. Flow Diagram of Participants 
Randomization was done with simple allocation. Herbal tea was produced by Medicinal Plants Research Institute of Iran under registration No. 771188. In this study, for measuring variables, we used a follow up form and tools for measuring growth parameters. For validity and reliability of the demographic questionnaire and the follow up form, content validity and test-retest method were used, respectively $(r=0.88)$. Before sampling, to confirm the reliability of the growth measuring tools, the researcher and another person measured the weight, height and head circumference of ten infants at the same time. After confirming the same results, measurements were performed by the researcher. To begin, the demographic questionnaires, including 12 questions about demographic conditions and six questions about breast-feeding conditions, were filled by the mothers. Before-intervention growth parameters included weight, height and head circumference of the infants, which were measured with the Seca scale made in Germany, tall-meter table and tape measure, respectively. Follow-up form was given to the mothers to measure pre-intervention conditions for the number of daily wet diapers, frequency of defecation and infant's breast-feeding times during two days. The mothers consumed the herbal tea weekly for four weeks, three times a day and two hours after each meal. Before each visit, the mother was reminded by phone contact about the next appointment and the herbal tea consumption times. During each visit the infant's weight was measured by the weight measurement scale, height by the tall-meter table and head circumference by the exact meter. The device was calibrated daily before and after the measurements. Infants were carefully weighed in the morning, after changing the infants' diapers, and before they were fed. The researcher strongly recommended to the mothers to complete the forms accurately. The followup form was given to the mothers to record the number of wet diapers during one day and frequency of defecation and infant's breast-feeding daily times during one week. During the four-week follow-up, the differences between breast milk sufficiency signs were evaluated and studied in the intervention and control group by using follow-up forms and growth parameter measurements. Examinations were performed by a physician according to the routines of the health care center and the mothers were asked to report any problems to the researcher.

The normally distributed data was checked by Kolmogorov-Simonov test and the normal distribution of the data was verified. Obtained data was analyzed using the statistical package for social sciences (SPSS) software version 20 and independent sample t-test and repeated measure analysis. All assumptions of repeated measurement were examined. P values of $<0.05$ were considered significant.

\section{Results}

In the present study, there were two groups of 39 participants (78 persons). All of them were entered to the statistical analysis and no sample loss occurred.

Some of the characteristics of the participants of the two groups are mentioned in Table 1. There was no significant difference between the two groups regarding mothers' BMI and age, and weight, height and head circumference of infants at the beginning of the study (Table 1).

Before the intervention there was no significant difference between the two groups regarding weight, height, head circumference and the number of wet diapers and frequency of defecation $(\mathrm{P}>0.05)$. However, the number of breast-feeding times in the control group was more than the fenugreek group $(\mathrm{P}<0.001)$ (Table 2$)$.

Considering time and intervention concurrency at the end of the fourth week compared to the pre-intervention conditions, weight, head circumference, the number of wet diapers, the frequency of defecation and the number breast feeding times of the infants of the fenugreek group significantly increased $(P<0.001)$. However, height growth was not significantly different between the two groups $(\mathrm{P}=0.078)$ (Table 3$)$.

Table 1. Characteristics of Participants According to Specific Groups ${ }^{a}$

\begin{tabular}{lccc}
\hline Group & Fenugreek $^{\mathrm{b}}$ & Control $^{\mathrm{b}}$ & P value $^{-}$ \\
\hline Mother age, $\mathbf{y}$ & $28.13 \pm 4.402$ & $29.49 \pm 4.855$ & 0.091 \\
\hline BMI, $\mathbf{~ k g} / \mathbf{m}^{\mathbf{2}}$ & $25.59 \pm 3.333$ & $24.87 \pm 3.254$ & 0.570 \\
\hline Infant age, day & $71.02 \pm 33.78$ & $61.82 \pm 32.76$ & 0.433 \\
\hline Infant weight, $\mathbf{g}$ & $5282.05 \pm 1021.51$ & $5334.87 \pm 1318.59$ & 0.519 \\
\hline Infant height, $\mathbf{c m}$ & $58.16 \pm 3.77$ & $57.05 \pm 4.68$ & 0.499 \\
\hline Infant head circumference, $\mathbf{c m}$ & $38.31 \pm 1.62$ & $38.60 \pm 2.11$ & 0.114 \\
\hline
\end{tabular}

a Abbreviations: BMI, Body Mass Index.

b Data are presented for $\mathrm{N}=39$. 
Ghasemi Vet al.

\begin{tabular}{lcc}
\hline \multicolumn{1}{l}{ Table 2. Comparison of the Signs of Breast Milk Sufficiency in the Fenugreek and Control Group Before Intervention } \\
\hline Variable & \multicolumn{1}{c}{ Mean $($ SD $)$} & P value \\
\hline Weight & & 0.844 \\
\hline Fenugreek & $5282.0513(1021.51121)$ & 0.250 \\
\hline Control & $5334.8718(1318.59948)$ & 0.492 \\
\hline Height & & \\
\hline Fenugreek & $58.1692(3.77458)$ & 0.072 \\
\hline Control & $57.0538(4.68041)$ & \\
\hline Head & & \\
\hline Fenugreek & $38.3103(1.62736)$ & 0.289 \\
\hline Control & $38.6051(2.11597)$ & \\
\hline Number of wet diapers & & \\
\hline Fenugreek & $5.2821(0.93044)$ & \\
\hline Control & $5.9231(1.68405)$ & \\
\hline Frequency of defecation & & \\
\hline Fenugreek & $1.8846(1.08495)$ & \\
\hline Control & $2.2051(1.52487)$ & \\
\hline Frequency of infant feeding & $9.1795(1.39778)$ & \\
\hline Fenugreek & $11.2051(2.07338)$ & \\
\hline Control & & \\
\hline
\end{tabular}

\begin{tabular}{|c|c|c|c|c|c|}
\hline Variable/Intervention & Week 1 & Week 2 & Week 3 & Week 4 & Pvalue \\
\hline Weight & & & & & $<0.001$ \\
\hline Fenugreek & $5597.1795(988.87482)$ & $5876.6667(963.55519)$ & $6137.1795(948.57497)$ & $6383.0769(952.06190)$ & \\
\hline Control & $5510.0000(1301.10479)$ & $5682.5641(1288.31125)$ & $5724.6154(1527.82929)$ & $6018.7179(1261.41353)$ & \\
\hline Height & & & & & 0.078 \\
\hline Fenugreek & $58.5949(3.64027)$ & $59.1179(3.54593)$ & $59.5385(3.44067)$ & $60.0769(3.49815)$ & \\
\hline Control & $57.3000(4.62089)$ & $57.6231(4.60552)$ & $57.8205(4.52096)$ & $58.9821(6.23951)$ & \\
\hline Head & & & & & $<0.001$ \\
\hline Fenugreek & $38.6641(1.58172)$ & 39.0949 (1.54510) & $39.4872(1.53025)$ & $39.9256(1.50660)$ & \\
\hline Control & $38.8487(2.03688)$ & $39.1282(2.02822)$ & $39.3923(2.02788)$ & $39.7769(2.00151)$ & \\
\hline Number of wet diapers & & & & & $<0.001$ \\
\hline Fenugreek & $6.2821(1.18959)$ & $7.2271(1.26496)$ & $7.7326(1.22373)$ & $8.1648(1.20620)$ & \\
\hline Control & $5.7985(1.64676)$ & $5.7143(1.50367)$ & $5.5275(1.53448)$ & $5.5788(1.46163)$ & \\
\hline $\begin{array}{l}\text { Frequency of defeca- } \\
\text { tion }\end{array}$ & & & & & $<0.001$ \\
\hline Fenugreek & $2.4176(1.08668)$ & $2.4396(0.98069)$ & $2.7766(0.90279)$ & $2.7326(0.94771)$ & \\
\hline Control & $2.0440(1.22635)$ & $1.8974(1.01331)$ & $1.8059(0.95859)$ & $1.7363(0.87053)$ & \\
\hline $\begin{array}{l}\text { Frequency of infant } \\
\text { feeding }\end{array}$ & & & & & $<0.001$ \\
\hline Fenugreek & $11.1758(1.66936)$ & $13.3297(1.59253)$ & $14.9853(1.41186)$ & $15.9597(1.45056)$ & \\
\hline Control & $10.9048(1.86215)$ & $11.2381(1.85290)$ & $11.5861(3.26370)$ & $11.4176(1.68470)$ & \\
\hline
\end{tabular}


Ghasemi Vet al.

\section{Discussion}

In this study the effect of herbal tea containing fenugreek seed on the signs of breast milk sufficiency, including infant's growth parameters such as weight, height and head circumference and also the number of wet diapers in one day, frequency of defecation and infant's breastfeeding times were evaluated in girl infants aged between 0 and 4 months, during four weeks. Our study showed improvement of the signs of breast milk sufficiency in the fenugreek group compared to the control group. However, the height growth of the infants was not influenced. With regards to the point that height growth in the first six months of birth has less improvement in comparison to weight, it seems reasonable for height growth in comparison to other variations to be less impressed.

In the study of Gabay et al. fenugreek was considered as a galactogogues plant, and it was mentioned that using fenugreek has been a custom since 1945 and women reported an increase in their milk production after 24 - 72 hours of use (13).

The results of our study support the results of many studies that inspected galactogogues properties of fenugreek with other variations.

In the study of El Sakka et al. (19), 75 mothers along with their infant were classified in three groups: herbal tea with fenugreek $(n=25)$, palm dates $(n=25)$ or no galactogogues as the control $(n=25)$. Maternal milk volume was measured through manual pumping of breasts on the third postpartum day. Infants were weighed on days 0,3 , 7 and 14 , using an infant scale. They concluded that breast milk volume on the third postpartum day was more in dates and fenugreek group as compared with the control group $(\mathrm{P}<0.001)$. Although there was a drop in weight after the three days in all groups, this drop was higher in the control group when compared to the fenugreek and dates groups; these differences were statistically significant between the control group and either intervention group, $\mathrm{P}$ $=0.001$. On the seventh day, newborns in the dates group showed an increase in weight $(2.9 \pm 4.5 \%)$ while those in the fenugreek or control groups were still below their birth weight $(\mathrm{P}=0.001)$. On the fourteenth day, there was no significant difference between the groups $(P=0.156)$. Therefore, the authors concluded that palm dates and fenugreek herbal tea seem to be useful for enhancing breast milk production during the early postpartum period (19). These data are in agreement with our study results.

In the study of Turkyilmaz et al. (14), 66 mothers along with their infants were classified in three groups: intervention group, receiving three cups of fenugreek daily, apple tea and control group. They concluded that fenugreek tea, increased breast milk volume $(73.2 \pm 53.5)$ in comparison to the control group $(31.1 \pm 12.9)(\mathrm{P}=0.004)$. The infants in the fenugreek group in comparison to the control group, lost less weight during the first week of birth (5.7 \pm 2.6 vs. $8.3 \pm 2.3)$ and gained their initial weight sooner than the other infants $(6.7 \pm 3.2$ vs. $9.9 \pm 3.5)(14)$.
Since in this study, fenugreek resulted in an increase of milk production, their findings confirm our study results. The results of the study by Dehkhoda et al. confirm that of our study regarding variations of breast feeding times and weight gain. The mothers received galactogogues pill containing fennel, fenugreek, cumin seed and dill and $10 \mathrm{mg}$ of metoclopramide pill. On the $14^{\text {th }}$ day of the study infant's breast feeding times in the intervention group was reported to be $5-12$ times in comparison to 1 - 7 times in the control group and infants' weight of the interference group was $1765.86 \pm 156.96 \mathrm{~g}$ in comparison to $1673.00 \pm 131.280 \mathrm{~g}$ in the control group (20).

Swafford's study on ten women at the end of the second week after giving birth showed significant differences in milk production. Milk production in the first week was considered as the base amount. In the second week the mothers drank three cups of fenugreek daily. The results showed that milk production increased from $207 \mathrm{~mL} /$ day in the first week to $464 \mathrm{~mL} /$ day in the second week. The results of this study confirm the galactogogues effect of fenugreek and are in line with the results of our study (21). However, the number of samples in this study are very few with this being one of its limitations.

The study of Damanik et al. on 75 women included three groups: Coleus amboinicus group, fenugreek group and moloco $+\mathrm{B}_{12}$ (reference group). The amount of milk production was converted to grams through measuring the weight difference of infants before and after each meal and by using $0.938 \mathrm{~mL} / \mathrm{g}$ factor was converted to $\mathrm{mL}$. The results showed a $65 \%$ increase of milk production in the group receiving Coleus amboinicus, 20\% in the fenugreek group, and $10 \%$ in the control group (18). According to the results, galactogogue of Coleus amboinicus is more than fenugreek, yet because there was no Coleus amboinicus in the country and since fenugreek is cheap and local in Iran, it was studied instead. In addition, the difference between results of this study with present study may be due to the dosage, medicine type and the method of calculating milk production.

The strength point of this study was the careful and continuous follow-up. The weak point of this study, despite the researcher's strong recommendations, may be shortcomings in the follow-up forms, which cannot be easily investigated. Herbal tea of fenugreek seed in comparison to the control group improved the signs of breast milk sufficiency.

\section{Acknowledgements}

This study was supported by the Tehran university of medical sciences. We are grateful to the south Tehran health center for their data collection and institute of medicinal plant (ACECR) for preparation of the Herbal tea.

\section{Authors' Contributions}

Vida Ghasemi participated in the data collection. Vida Ghasemi and Masoomeh Kheirkhah participated in the design and writing of the manuscript. Mohsen Vahedi 
contributed to the analysis of the data. All authors approved the final version submitted for publication.

\section{Funding/Support}

This study was supported financially by the Tehran university of medical sciences.

\section{References}

1. Walker A. Breast milk as the gold standard for protective nutrients. J Pediatr. 2010;156(2 Suppl):S3-7.

2. WHO, Unicef . Global Strategy on Infant and Young Child Feeding. 55th World Health Assembly. In: World Health Organization, editor. Geneva: 2003.

3. Chung M, Raman G, Chew P, Magula N, DeVine D, et al. Breastfeeding and maternal and infant health outcomes in developed countries. Evid Rep Technol Assess (Full Rep). 2007;(153):1-186.

4. James DC, Lessen R, American Dietetic A. Position of the American Dietetic Association: promoting and supporting breastfeeding. J Am Diet Assoc. 2009;109(11):1926-42.

5. Horta BL, Bahl R, Martines JC, Victora CG. Evidence on the longterm effects of breastfeeding. Systematic reviews and meta-analyses. Geneva: WHO; 2007.

6. Edmond KM, Zandoh C, Quigley MA, Amenga-Etego S, OwusuAgyei S, Kirkwood BR. Delayed breastfeeding initiation increases risk of neonatal mortality. Pediatrics. 2006;117(3):e380-6.

7. WHO. Infant and young child feeding: model chapter for textbooks for medical students and allied health professionals. Geneva: World Health Organization; 2009.

8. Nkala TE, Msuya SE. Prevalence and predictors of exclusive breastfeeding among women in Kigoma region, Western Tan zania: a community based cross-sectional study. Int Breastfeed J. 2011;6(1):17.

9. Olang B, Farivar K, Heidarzadeh A, Strandvik B, Yngve A. Breast- feeding in Iran: prevalence, duration and current recommendations. Int Breastfeed J. 2009;4:8.

10. Mannel R, Martens PJ, Walker M. Core curriculum for lactation consultant practice. In: Hoover K, Marasco L, editors. insufficient Milk Production. USA: Jones \& Bartlett Publishers; 2012.

11. Amini M, Salarkia N, Eshrati B, Djazayery A. Poor Breastfeeding as a Probable Cause of Childhood Malnutrition: Exploring Mothers' and Caregivers' Views on Breastfeeding via a Qualitative Study in Damavand, Iran. Razavi Int J Med. 2013;1(1):30-4.

12. Olang B, Heidarzadeh A, Strandvik B, Yngve A. Reasons given by mothers for discontinuing breastfeeding in Iran. Int Breastfeed $J$. 2012;7(1):7.

13. Gabay MP. Galactogogues: medications that induce lactation. Hum Lact. 2002;18(3):274-9.

14. Turkyilmaz C, Onal E, Hirfanoglu IM, Turan O, Koc E, Ergenekon $\mathrm{E}$, et al. The effect of galactagogue herbal tea on breast milk production and short-term catch-up of birth weight in the first week of life. J Altern Complement Med. 2011;17(2):139-42.

15. Mir Heydar H. Plant Sciences: used in the prevention and treatment plants. 9th ed. Tehran: Office of Islamic culture; 2010. pp. 145-9.

16. Patisaul HB, Jefferson W. The pros and cons of phytoestrogens. Front Neuroendocrinol. 2010;31(4):400-19.

17. Lawrence RA, Lawrence RM. Breastfeeding: A Guide for the Medical Profession. 6th ed. Philadelphia: Elsevier Mosby; 2005.

18. Damanik R, Wahlqvist ML, Wattanapenpaiboon N. Lactagogue effects of Torbangun, a Bataknese traditional cuisine. Asia Pac $J$ Clin Nutr. 2006;15(2):267-74.

19. El Sakka A, Salama M, Salama K. The Effect of Fenugreek Herbal Tea and Palm Dates on Breast Milk Production and Infant Weight. JPediatrSci. 2014;6(e202)

20. Dehkhoda N, Valizadeh S, Jodeiry B, Hosseini MB. The effects of an educational and supportive relactation program on weight gain of preterm infants. J Caring Sci. 2013;2(2):97-103.

21. Swafford S, Berens P. Effect of fenugreek on breast milk production; Abstract 5th International Meeting of the Academy of Breastfeeding Medicine; 11 Sept 2013; 2000. 